\title{
A Simplified Methodology for Rapidly Analyzing the Effect of Multi-Hazard Scenario on Atmospheric Storage Tanks
}

\section{Jiajun Wang}

Tsinghua University

Wenguo Weng ( $\nabla$ wgweng@tsinghua.edu.cn )

Institute of Public Safety Research https://orcid.org/0000-0003-0834-8338

\section{Research Article}

Keywords: Natech, multi-hazard, flood, wind, hail, storage tank, vulnerability, Monte Carlo simulation

Posted Date: December 15th, 2021

DOI: https://doi.org/10.21203/rs.3.rs-1119680/v1

License: (c) (i) This work is licensed under a Creative Commons Attribution 4.0 International License.

Read Full License 


\title{
A simplified methodology for rapidly analyzing the effect of multi-
}

\section{hazard scenario on atmospheric storage tanks}

3 Author names: Jiajun Wang a,b , Wenguo Weng a,b

\section{Affiliation:}

$5 \quad{ }^{\text {a }}$ Institute of Public Safety Research, Department of Engineering Physics, Tsinghua University

$6 \quad{ }^{b}$ Beijing Key Laboratory of Comprehensive Emergency Response Science

7 Postal address: Institute of Public Safety Research, Department of Engineering Physics, Tsinghua

8 University, Beijing, 100084, China

9 E-mail: wang-jj19@mails.tsinghua.edu.cn,wgweng@tsinghua.edu.cn

Corresponding author: Wenguo Weng

Postal address: Institute of Public Safety Research, Department of Engineering Physics, Tsinghua

University, Beijing, 100084, China

14 E-mail: wgweng@tsinghua.edu.cn

Tel: $+86-10-62796917$

Fax: $+86-10-62792863$

Keywords: Natech; multi-hazard; flood; wind; hail; storage tank; vulnerability; Monte Carlo simulation

\begin{abstract}
Natural hazard events that trigger technical emergencies (Natech events), as a typical type of multi-hazard, have become a matter of growing concern. In particular, the occurrence of Natech events in industrial areas triggered a number of severe accidents. The present research aims at introducing a sound but simplified methodology to quickly and flexibly assess the vulnerability of atmospheric storage tanks to multiple natural disasters in Natech events. This method consists of 8 steps, relying on the simplified physical models of tank damage caused by natural disasters. The models of wind overturning tank and tank buckling caused by hail are proposed. In addition, the assessment process of tank vulnerability is demonstrated from two aspects: deterministic analysis and probabilistic analysis. The uncertain parameter set (UPS) proposed in the method and the Monte Carlo simulation method can help to purposefully analyze the impact of various parameters and this method is also a general method, which is also applicable to Natech events including other natural disasters or other types of storage tanks.
\end{abstract}


Declarations

33

Funding

The National Science Fund for Distinguished Young Scholars of China (71725006) and National Natural Science Foundation of China (72034004).

36

\section{Declaration of Interest Statement}

38

The authors declare no competing financial interests.

39

40

Availability of data and material

41

Available. 


\section{Introduction}

As global problems such as climate change, population growth, resource shortage, etc., have emerged, the living environment of human beings is facing increasingly severe challenges. Especially in recent decades, with the development of human society, the impact of natural disasters is also increasing, resulting in many casualties and economic losses. Among them, natural hazard events that trigger technical emergencies (Natech events) (Showalter and Myers 1994), as a typical type of multi-hazard (Wang et al. 2020), have become a matter of growing concern. In particular, the occurrence of Natech events in industrial areas triggered a number of severe accidents.

In industrial areas, natural disasters such as strong earthquakes, strong winds, landslides, floods, etc., will directly cause damage to industrial equipment (Cruz et al. 2008), which may lead to the loss of containment. In industrial areas, natural disasters such as strong earthquakes, strong winds, landslides, floods, etc., will directly cause damage to industrial equipment, which may lead to the loss of containment (LOC). In chemical plants, LOC of hazardous substances may lead to fire, explosion and leakage of toxic substances. This will undoubtedly aggravate the impact of natural disasters on regional safety. Hurricanes Katrina and Rita, which occurred in 2005, hit the industrial intensive areas along the Gulf coast of Mexico in the United States, causing a huge blow to the local industrial facilities, resulting in the leakage of a large number of oil and dangerous substances, seriously affecting the ecological environment (Cruz et al. 2009). According to the National Petrochemical \& Refiners Association, the hurricane caused about $50 \%$ of the oil production and about $25 \%$ of the natural gas production loss in the United States, which affected about $20 \%$ of the refining capacity in the United States. At least 200 hazardous chemicals emissions have occurred in coastal chemical companies due to the damage of hurricanes. In total, more than 1300 people died and economic losses are estimated to exceed $\$ 100$ billion during the hurricane (Godoy 2007).

Therefore, risk of Natech events has started to be recognized in risk assessment of industrial areas in recent decades. In addition to the statistical analysis of Natech events and case studies, most attempts are devoted to quantitative research on the damage process of industrial areas caused by natural disasters, including the damage model and vulnerability assessment of industrial facilities to earthquake, flood, lightning, tsunami and other natural disasters (Wang et al. 2020). In the early research, researchers got qualitative mechanism through the statistics of historical data, trying to build the vulnerability curve of industrial facilities (Antonioni et al. 2009), but it is not completely reliable. Afterwards, limit state equations (LSEs) have been developed for different damage modes which in turn can be used to determine the likelihood of damages deterministically or probabilistically (Khakzad et al. 2018). Researchers intend to build sound but simplified physical models based on the damage mechanism of industrial facilities affected by natural disasters (Landucci et al. 2012; Landucci at al. 2014). However, in previous studies, usually only one damage mode is considered or multiple damage modes are considered independently. This ignores the case where multiple damage modes are caused by the same parameter, making them not completely independent. In addition, when considering specific natural disasters, only one natural disaster scenario is usually considered at a time, and the compound scenario of multiple natural disasters is rarely studied, in which the interaction between natural disasters needs to be further added.

Due to their design and purpose, atmospheric storage tanks are vulnerable to Natech events, including earthquakes (Huang et al. 2020), tsunamis (Cruz et al. 2011), volcanic effects (Milazzo et al.), flooding (Elisabeth et al. 2008) and strong winds (Olivar et al. 2020). As mentioned above, strong winds caused 
very serious Natech events along the Gulf coast of Mexico in the United States. In fact, when strong wind weather occurs, it is often accompanied by heavy precipitation, which leads to floods. Moreover, it is often neglected in the previous research of Natech events that when the temperature drops sharply, heavy precipitation will appear in the form of hail (Sioutas 2017). These small balls made of ice will also cause great impact on the storage tank, which has hardly been involved in the previous research on the impact of natural disasters on industrial facilities. The simultaneous occurrence of multiple natural disasters and technical accidents caused by them constitutes multiple threats. Therefore, it is very possible to have a multi-hazard scenario in which strong wind, flood and hail will damage the storage tanks. It is necessary to consider multiple damage modes caused by multiple natural disasters at the same time, and to study the possible interaction between natural disasters.

The present study is aimed at introducing a sound but simplified methodology to quickly and flexibly assess the vulnerability of atmospheric storage tanks to multiple natural hazards. This method relies on the simplified physical models of tank damage caused by natural disasters, based on which the LSEs and vulnerability curves (surfaces) are constructed. Furthermore, the uncertain parameter set (UPS) of natural disasters and storage tanks are extracted from the simplified physical models. Then, Monte Carlo method is used to simulate the uncertainty of parameters. Finally, the likelihood of damages is determined probabilistically by using the LSEs and UPS. This method can conveniently consider multiple natural disasters and multiple damage modes at the same time, and can also reflect the interaction of natural disasters in Natech events through UPS. This method is also a general method, which is also applicable to Natech events including other natural disasters or other types of storage tanks.

The following parts of the paper are organized as follows. The methodology proposed for vulnerability assessment of atmospheric storage tanks to natural disasters is described in Section 2. An illustrative example is presented in Section 3 by using one storage tank to demonstrate the complete process and results of the methodology and by using multiple storage tanks to do the comparison. Section 4 reports the conclusions.

\section{Methodology}

\subsection{Overview}

Fig. 1 outlines the methodology developed in the present study. The proposed procedure allows the analysis of the effect of natural disasters on storage tanks from the aspects of damage conditions, resistance against damage and damage probability calculation. Considering the variability of the actual situation, Monte Carlo method provides convenient conditions for simulating the uncertainty of natural disasters and the uncertainty of tank parameters in industrial areas. The key is to extract the UPS, using which the probability of tank damage can be evaluated quickly. The methodology comprises the following four parts.

i. Defining the reference research objects and performing a characterization of their main features (Steps 1-3). The parameters used to describe the characteristics of natural disasters refer to the physical quantities that physically affect the storage tank. The type of storage tanks that may be affected by natural disasters need to be determined. Due to the different physical characteristics of different storage tanks, the physical quantities related to the storage tank itself that will determine the impact of natural disasters should be found after selecting the 
type of storage tank to be studied. Different natural disasters cause different types of damage to storage tanks, which needs to be analyzed in detail.

ii. Simplified physical models of Natech damage and limit state equations (Step 4). According to the characteristic description of natural disasters and storage tanks, after determining the failure type, the physical analysis of the failure process is carried out. The physical formula is deduced and sorted out, and the condition equation of failure, that is, the limit state equation, is obtained.

iii. Deterministic analysis of damage conditions (Steps 5-6). Based on LSEs, the damage conditions can be analyzed from two aspects: natural disasters and storage tanks. When the

Fig. 1. Methodology proposed for rapid and flexible vulnerability assessment of atmospheric storage tanks to natural disasters (LSEs: limit state equations).

\subsection{Defining the reference research objects and performing a characterization of their main}

\section{features}

\subsubsection{Characterization of natural disasters}

For natural disasters, we are concerned about their intensity and frequency. Frequency is usually described by return period. Of course, when studying a specific natural disaster scenario, we only care about the intensity of the natural disaster itself in this process.

As mentioned in Section 1, it is very possible to have a compound scenario in which strong wind, 
flood and hail will damage the storage tanks. In the specific framework of Natech, the severity of floods may be characterized in terms of flood water height and velocity, which determines the strength of static pressure and dynamic pressure on the storage tank, while the magnitude of strong winds is commonly assessed estimating the values of wind speed, which determines the strength of the wind load on the storage tank. When hail impacts on industrial facilities, the speed and diameter play a decisive role (a hail stone is approximately regarded as a sphere, and the density is the density of ice). However, as hail often falls from extremely high air, its vertical velocity is generally regarded as reaching the terminal velocity. Through the later derivation, it can be found that this velocity is also determined by its diameter. In the horizontal direction, the wind will give hail a certain horizontal velocity. Therefore, the diameter of hail and the wind speed at that time are decisive.

There are some classification methods to classify natural disasters based on their intensity parameters, such as the classification of hurricanes based on the Saffir / Simpson scale (Potter and Colman 2003). However, we do not rely on the classification of natural disasters for calculation, so it only needs to obtain the strength parameter values of natural disasters according to some references to characterize them.

\subsubsection{Characterization of target equipment}

According to Antonioni et al. (2009), the analysis of historical data evidenced that atmospheric storage tanks having a large inventory of flammable or toxic substances, should be considered as the more critical equipment items in the assessment of risk due to natural events.

For atmospheric vertical storage tank, it is approximated as a thin-shelled closed cylinder, mainly focusing on its diameter, height, shell thickness and shell material. In addition, the tank also involves the characteristics of roof and base, which will be further discussed in the process of physical derivation.

\subsubsection{Damage type analysis}

Each natural disaster will cause different damage modes to the storage tanks. According to the literature and previous studies (Antonioni et al. 2009; Landucci et al. 2012; Schoenherr 2015; Olivar 2020), there are mainly the following damage modes: i) the buckling of tank shell caused by flood and wind load; ii) tank floating due to flooding; iii) displacement of tanks due to flooding; iv) tank overturning due to wind force; v) shell material yielding due to hail strike. Note that here we use damage rather than failure to indicate that the structure and state of the tank itself have been damaged, or changed. This is not equivalent to the LOC mentioned in Section 1, because the destruction of structure and state does not necessarily lead to the loss of containment. Failure is usually used in the study to indicate the occurrence of LOC and subsequent processes that may lead to fire, explosion, etc. In the present study, only the process of tank damage caused by natural disasters is considered, and the process from damage to failure is not further studied.

\section{- Buckling}

Buckling is the damage of tank caused by external load, which is usually manifested in the instability, bending and even fracture of tank shell. The most critical physical quantity related to buckling is the critical pressure $P_{c r}$ of the tank shell. When the pressure acting on the tank shell exceeds the critical pressure $P_{c r}$, it will lead to buckling damage. The critical pressure can be calculated by the following equation according to the mechanical properties of the tank (Timoshenko and Gere 1963): 


$$
P_{c r}=\frac{2 E t}{D}\left\{\frac{1}{\left(n^{2}-1\right)\left[1+\left(\frac{2 n H}{\pi D}\right)^{2}\right]}+\frac{t^{2}}{3 D^{2}\left(1-v^{2}\right)}\left[n^{2}-1+\frac{2 n^{2}-1-v}{1+\left(\frac{2 n H}{\pi D}\right)^{2}}\right]\right\}
$$

where $E$ is the Young's modulus of the tank material; $v$ is Poisson ratio; $n$ is the number of waves involved in buckling. $D, t$, and $H$ are the diameter, shell thickness and height of the storage tank respectively. Since it is difficult to determine the number of waves involved in buckling $(n)$ in practice, the simplified equation of Eq. (1) (Xu et al. 2005) is often used to calculate the critical pressure $P_{c r}$ :

$$
\begin{aligned}
& P_{c r}=\frac{2 E}{1-v^{2}}\left(\frac{t}{D}\right)^{3} \quad \text { for slender-long tanks with } H \geq H_{c r} \\
& P_{c r}=\frac{2.59 E t^{2.5}}{H D^{1.5}} \quad \text { for thick-short tanks with } H<H_{c r}
\end{aligned}
$$

where critical height

$$
H_{c r}=1.17 D \sqrt{D / t}
$$

According to this standard, the vast majority of tanks are thick-short tanks and are applicable to Eq. (3). Therefore, when the physical properties of a storage tank are determined, its critical pressure $P_{c r}$ is also determined.

\section{- Floating}

Floating refers to the damage mode that the buoyancy generated by flood on the storage tank is greater than the gravity of the storage tank and its contents, resulting in the storage tank leaving the ground and floating in the water.

\section{- Displacement}

Displacement refers to the damage process that the storage tank is forced to leave its original position due to the pressure of flood. This damage mode is generally generated by the non-anchored storage tank. Khakzad et al. (2018) pointed out that the dynamic pressure of flood caused the tank to slide, resulting in structural damage due to friction with the ground, and believed that if the tank floated, there would be no sliding. However, the displacement in present study does not only refer to the sliding of the tank (friction with the ground), but also refers to the change of the position of the tank (displacement). Under the definition of this paper, on the contrary to Khakzad et al. (2018), if the tank floats, the displacement damage may have occurred. Although the displacement in the floating state will not lead to friction with the ground, it may lead to the separation of the connected pipeline, resulting in more serious consequences.

\section{- Overturning}

Overturning is the damage mode caused by the wind overturning the storage tank when the moment generated by the strong wind on the storage tank is greater than the moment of the storage tank and its contents.

\section{- Yielding}

Yielding is also the tank damage caused by external load. Different from buckling, buckling refers to the structural instability of the tank, and yielding is the characteristic of the tank material itself. When the stress exceeds the elastic limit of the tank material, it will yield and begin to produce unrecoverable plastic deformation, resulting in the damage of the tank.

\subsection{Simplified physical models of Natech damage and LSEs (Step 4)}

\subsubsection{Flood-induced damage}


Flood can cause tank buckling, floating and displacement, and its pressure on the tank is composed of dynamic pressure and static pressure. For the buckling of the tank shell, the buckling occurs when the net pressure $\left(P_{n e t}\right)$ acting on the tank shell exceeds the critical pressure $\left(P_{c r}\right)$ of the tank. According to previous research and literature (Landucci et al. 2012; Khakzad et al. 2018; Qin et al. 2020), we can get:

$$
\begin{aligned}
P_{n e t} & =P_{f s}+P_{f d}-P_{l} \\
& =\rho_{f} g h_{f}+\frac{1}{2} C_{f} \rho_{f} v_{f}^{2}-\rho_{l} g h_{l}
\end{aligned}
$$

Where, $P_{f s}, P_{f d}, P_{l}$ are the static pressure of flood, the dynamic pressure of flood and the pressure of the liquid stored in the storage tank respectively. And $\rho_{f}, h_{l}$, and $v_{f}$ are the density, inundation height and velocity of flood respectively. $C_{f}$ is the flow resistance coefficient, which is related to the properties of the flood itself and the shape of the storage tank. $\rho_{l}$ and $h_{l}$ are the density and height of the liquid stored in the storage tank. $g$ is the local gravitational acceleration. When $P_{\text {net }}-P_{c r}>0$, the tank will buckle, so the LSE of tank buckling is (damage occurs when LSE is greater than 0).

$$
L S E_{f b}=P_{f s}+P_{f d}-P_{l}-P_{c r}
$$

For non-anchored tanks, when the buoyancy generated by flood on the tank exceeds the weight of the tank itself and the liquid in the tank, the floating damage will occur, and its LSE is:

$$
\begin{aligned}
L S E_{f f} & =F_{b}-\left(G_{T}+G_{l}\right) \\
& =\rho_{f} g \frac{\pi D^{2}}{4} h_{f}-\rho_{s} g\left(\pi D H+\frac{\pi D^{2}}{2}\right) t-\rho_{l} g \frac{\pi D^{2}}{4} \mathrm{~h}_{l}
\end{aligned}
$$

where $F_{b}$ is the buoyancy of flood, $G_{T}$ is the gravity of the storage tank, $G_{l}$ is the gravity of liquid in tank and $\rho_{s}$ is the density of storage tank material, which is generally the density of steel.

The dynamic pressure of flood will push the storage tank and cause the displacement of the storage tank. Obviously, displacement occurs when the friction between the tank and the ground and the force between the tank and the connecting pipeline (if any) are not enough to resist the dynamic pressure of flood. Therefore, its LSE can be developed as:

$$
\begin{aligned}
L S E_{f d} & =F_{f d}-F_{f r}-F_{0} \\
& =P_{f d} D h_{f}-\mu\left(G_{T}+G_{l}-F_{b}\right)-F_{0}
\end{aligned}
$$

where $F_{0}$ is the force between the tank and the connecting pipeline (maybe it doesn't exist), and $F_{f d}$ is the thrust generated by the dynamic pressure of flood, $F_{f r}$ is the friction of ground to tank, and $\mu$ is the dynamic friction coefficient between the tank and the ground. It should be noted that when the tank doesn't have any connected pipelines $\left(F_{0}=0\right)$ and when $L S E_{f f}$ is greater than 0 , it can be seen that the friction $F_{f r}$ between the ground and the storage tank is less than 0 (actually impossible because the minimum friction is 0 ), which means $L S E_{f d}$ must be greater than 0 . And if the tank has a connected pipeline, when the tank floats, the displacement of the tank depends on the values of $F_{f d}$ and $F_{0}$. When $F_{f d}>F_{0}$, tank displaces, leading to the separation of the connected pipeline. This confirms that if the tank floats, displacement damage may have occurred, as is mentioned in Section 2.2.3.

\subsubsection{Wind-induced damage}

Strong wind will cause buckling and overturning of storage tanks. Similar to the mode of buckling caused by flood, buckling occurs when the net pressure $\left(P_{n e t}\right)$ of wind acting on the tank shell exceeds the critical pressure $\left(P_{c r}\right)$ of the tank. The wind load is also composed of dynamic pressure and static pressure. Static pressure is the atmospheric pressure. For atmospheric storage tanks, the internal and 
external atmospheric static pressures are equal and offset each other. Therefore, only the dynamic pressure of wind can be considered. Like the dynamic pressure of flood, the dynamic pressure of wind also has the following forms:

$$
P_{w d}=\frac{1}{2} C_{w} \rho_{a} v_{w}^{2}
$$

where $\rho_{a}$ is the density of air, $v_{w}$ is the speed of the wind, and $C_{w}$ as a coefficient contains very complex content. The European Committee for Standardization proposed the wind coefficient (European Committee for Standardization 2007), which was given by the Fourier formula in the previous study (Greiner and Derler 1995). And, it is assumed that the wind pressure is constant in the height range of the tank, and a constant equivalent uniform external pressure $q_{e q}$ in the perimeter range of the tank acts on the tank surface, the relationship between which and wind pressure is related to an equivalent coefficient (Olivar et al. 2020). Since predecessors have done detailed research, it is unnecessary to go into detailed derivation process here. Therefore, the LSE of tank buckling caused by strong wind can be developed as:

$$
L S E_{w b}=q_{e q}-P_{l}-P_{c r}
$$

where the critical pressure and the pressure of the liquid stored in the tank are the same as the calculation process of buckling caused by flood.

Strong winds can also cause overturning of (non-anchored) tanks, which is related to the balance of moments. It is worth noting that in the process of tank from upright to overturning, with the change of tank position and the different liquid level height in the tank, the liquid in the tank will form different truncated cylinder shapes, which will make it very difficult to calculate the center of gravity of the liquid. Considering that most storage tanks have floating roof structure, which can keep the liquid level shape unchanged, based on which we make a simplified derivation of the tank overturning process, as shown in Fig. 2. In order to calculate the relevant moment, firstly, it is necessary to determine the height $y_{c}$ between the center of gravity of the tank and the whole liquid in the tank and the bottom of the tank:

$$
y_{c}=\frac{G_{T} y_{T}+G_{l} y_{l}}{G_{T}+G_{l}}
$$

Where $y_{T}$ and $y_{l}$ are the height of the gravity center of the tank itself and the height of the liquid gravity center in the tank, which are respectively equal to half of the height $H$ of the tank itself and the liquid height $h_{l}$.

It is assumed that the included angle between the bottom and the ground is $\theta$, then the moment generated by the wind on the storage tank is:

$$
M_{w}=q_{e q} D H \cos \theta\left(\frac{1}{2} H \cos \theta+D \sin \theta\right)
$$

The resistance moment generated by the tank and liquid is

$$
M_{T l}=\left(G_{T}+G_{l}\right)\left(\frac{1}{2} D \cos \theta-y_{c} \sin \theta\right)
$$

When the vertical line of the center of gravity of the tank and the liquid exceeds the of the support point, the tank will fall to the ground. According to the geometric properties, the critical included angle $\theta_{0}$ meets:

$$
\tan \theta_{0}=\frac{D}{2 y_{c}}
$$

In this way, the LSE of tank overturning caused by strong wind can be developed as:

$$
L S E_{w o}=M_{w}-M_{T l} \quad \theta \in\left(0, \tan ^{-1} \frac{D}{2 y_{c}}\right)
$$




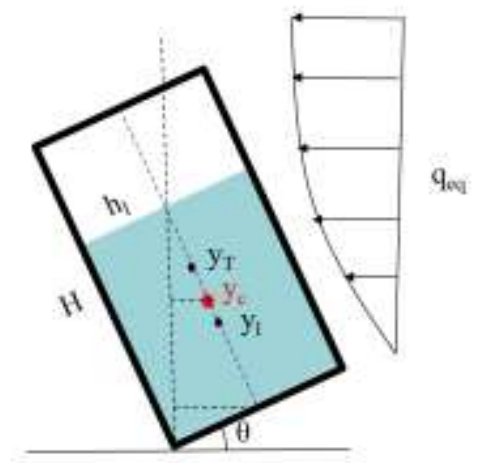

Fig. 2. Schematic diagram of wind overturning storage tank.

\subsubsection{Hail-induced damage}

When a hailstone acts on the storage tank, as mentioned in 2.2.1, the velocity $v_{y}$ of it in the vertical direction can be regarded as reaching its ending speed. At this time, the gravity of hailstone equals to the resistance of air to the hailstone, which can be expressed as:

$$
\frac{1}{2} C_{h} \rho_{a} v_{y}^{2} A=m_{h} g
$$

where $C_{\mathrm{h}}$ is the resistance coefficient of air to hailstone, and $A$ is the cross-sectional area of hailstone, $m_{\mathrm{h}}$ is the mass of hailstone. Thinking of the hailstone as a sphere having a diameter of $d$ and a density of $\rho_{\mathrm{h}}$, then according to the area formula of the cross-section circle and the volume formula of the sphere we can get:

$$
v_{y}^{2}=\frac{4}{3} \times \frac{\rho_{h} g d}{\rho_{a} C_{h}}
$$

If there is strong wind at that time, the hailstone will be accelerated by the wind in the horizontal direction, and there will be a certain speed $v_{x}$. In this way, the hailstone will impact the tank shell at an angle $\alpha$ of incidence, as shown in Fig. 3.

In this way, the impact of hailstone on the storage tank becomes a problem of impact load, which is a very complex process. In order to obtain the physical model of hail impacting the storage tank, three assumptions are made here to simplify the problem: i) the impact process is an elastic process, in which the mechanical energy is conserved, that is, the kinetic energy of hailstone is transformed into the strain energy of tank shell; ii) maximum impact load at maximum strain; iii) hailstone will not completely enter the tank shell. A "rod-shaped element" can be taken, and the shear force between the "rod" and the adjacent part can be ignored, and the stiffness coefficient $k$ of the "rod" can be calculated by using the Young's modulus:

$$
k=\frac{E A}{l}=\frac{\pi E d^{2} \sin \alpha}{4 t}
$$

When the kinetic energy of hailstone is converted into the strain energy of tank shell, there are:

$$
\begin{aligned}
\frac{1}{2} m_{h} v^{2} & =\frac{1}{2} k \Delta d_{m}^{2} \\
F_{h m} & =k \Delta d_{m} \\
p_{h m} & =\frac{F_{h m}}{A}
\end{aligned}
$$


where $\Delta d_{m}$ is the maximum deformation of the tank shell, $F_{h m}$ is the maximum impact force of hailstone on the tank, and $p_{h m}$ is the maximum pressure of hailstone on the tank. Substituting the expression of each variable into Eq. (21), we can get:

$$
p_{\mathrm{hm}}=\sqrt{\frac{8}{9} \frac{E d^{2} \rho_{h}^{2} g}{t \rho_{a} C_{h}} \frac{\sin \alpha}{\cos ^{2} \alpha}}
$$

where the incidence angle $\alpha$ meets:

$$
\tan \alpha=\frac{v_{x}}{v_{y}}
$$

Thus, when the yield strength of the tank material is $Q_{S}$, the LSE of tank yield caused by hail can be developed as follows:

$$
L S E_{\mathrm{hy}}=p_{h m}-Q_{s}
$$

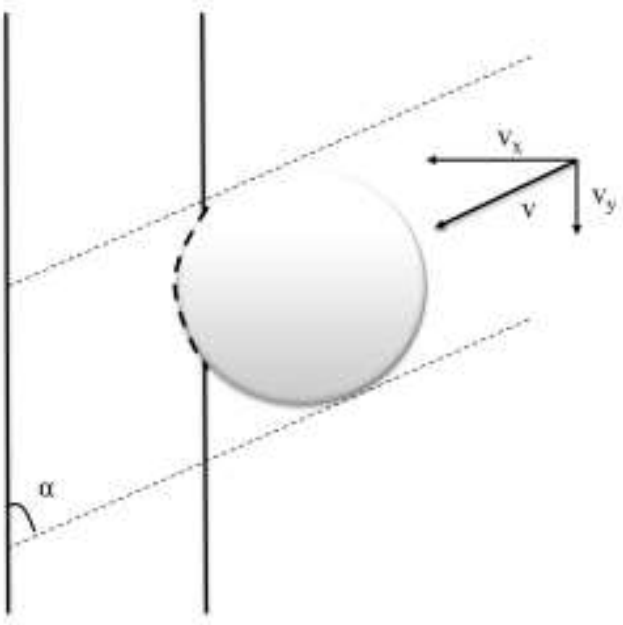

Fig. 3. Schematic diagram of hail impacting tank.

\subsection{Deterministic analysis of damage conditions (Steps 5-6)}

The developed simplified physical models of Natech damage and LSEs allow the calculation of damage conditions. As mentioned in the discussion in Section 2.3, damage occurs when the value of LSE is greater than 0. From a mathematical point of view, this is a deterministic result. The LSE value is determined by two aspects: the natural disaster intensity parameters (mentioned in Section 2.2.1) and the properties of the storage tanks (mentioned in Section 2.2.2). This makes it possible to analyze the damage of storage tanks from two perspectives. On the one hand, when considering the determined tank, the intensity threshold causing tank damage can be derived from LSE, which is usually represented by the vulnerability curve. The natural disaster intensity parameter represented by the area above the vulnerability curve indicates that the natural disaster will damage the storage tank. On the other hand, based on LSEs, we can analyze what kind of storage tank is more resistant to damage under the influence of natural disasters, or how the parameters of storage tank affect the limit state of damage. Next, we will analyze these two aspects respectively. 


\subsubsection{Vulnerability curve}

As mentioned in Section 2.2.1, the key parameters determining the intensity of natural disasters are deterministic: flood parameters $\left(v_{f}, h_{f}\right)$, strong wind parameter $\left(v_{w}\right)$, hail parameters $\left(d, v_{x}\right)$, which can also be derived from the physical derivation in Section 2.3. On this basis, the properties of the tank and the liquid in the tank are considered to be fixed, and some key coefficients (such as resistance coefficient, friction coefficient, etc.) are also recognized as constants. By changing the form of LSEs and extracting the natural disaster parameters, we can see how the natural disaster parameters or their combination affect the tank damage.

\section{i. Flood-induced damage}

For flood damage, the following form can be obtained by extracting flood parameters $\left(v_{f}, h_{f}\right)$ from $L S E_{f b}$ :

$$
\text { flood }_{\text {buckling }}: \quad v_{f}^{2}=-k_{1} h_{f}+k_{2}
$$

which shows that the vulnerability curve composed of $v_{f}^{2}$ and $h_{f}$ has a linear relationship for tank buckling caused by flood. Similarly, by analyzing $L S E_{f f}$ and $L S E_{f d}$ respectively, we can get:

$$
\begin{gathered}
\text { flood }_{\text {floating: }}: \quad h_{f}=k_{3} \\
\text { flood }_{\text {displacement }}: \quad v_{f}^{2}=\frac{k_{4}}{h_{f}}\left(G_{T}+G_{l}-F_{b}\right)+\frac{k_{5}}{h_{f}} F_{0}
\end{gathered}
$$

It can be seen that the floating of storage tank caused by flood is only related to the inundation depth $h_{f}$ of flood. Basically, the relationship curve between $v_{f}^{2}$ and $h_{f}$ have the shape of inverse proportional function for tank displacement caused by flood. It is worth noting that after the value of $h_{f}$ (set this value as $h_{f f}$ ) meets the floating conditions, the buoyancy generated by the flood is no longer related to $h_{f}$, but will be equal to the gravity of the tank and the liquid because of the physical characteristics of tank floating, which makes the first term on the right in Eq. (27) constant to 0 when $h_{f}$ is greater than $h_{f f}$, resulting in a sudden change in the shape of the vulnerability curve. The second term on the right in Eq. (27) is related to the force of the connecting pipelines on the storage tank. If there are no connecting pipelines in the storage tank, the second term on the right does not exist. Thus, after $h_{f}$ is greater than $h_{f f}, v_{f}^{2}$ will always be equal to 0 in the vulnerability curve. Its physical meaning is that if the tank floats and there are no pipelines connected, the tank will displace as long as the flood has a certain speed $\left(v_{f}>\right.$ 0 ). The vulnerability curve of tank damage caused by flood (with or without pipeline connection) is shown in Fig. 4, which also shows that the three damage modes caused by flood are not independent.

\section{ii. Strong-wind-induced damage}

For strong wind, because the atmospheric pressure changes relatively little, the wind speed $v_{w}$ is usually decisive whether it is the dynamic pressure generated by the wind or the moment when the wind overturns the storage tank. Therefore, for the damage caused by strong wind to the storage tank, there is no vulnerability "curve", but vulnerability "point". When the value of wind speed $v_{w}$ meets the conditions of buckling or overturning, the damage will occur. 


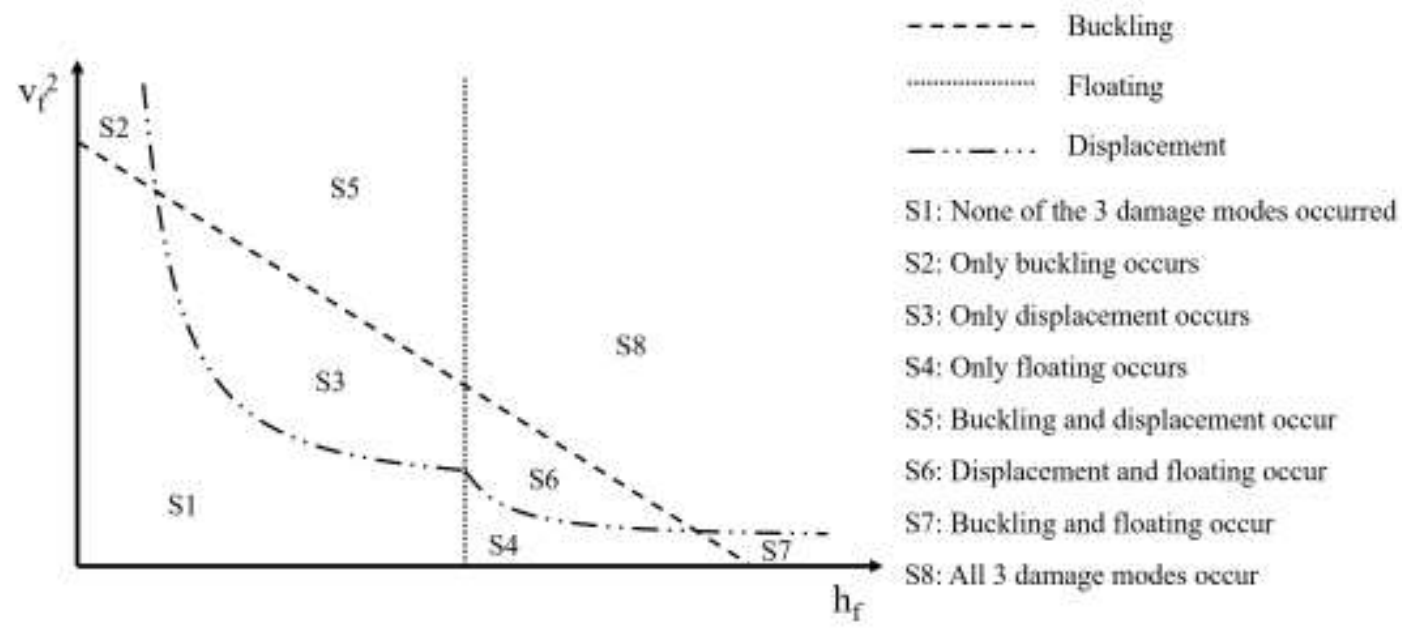

(a) with pipeline connection

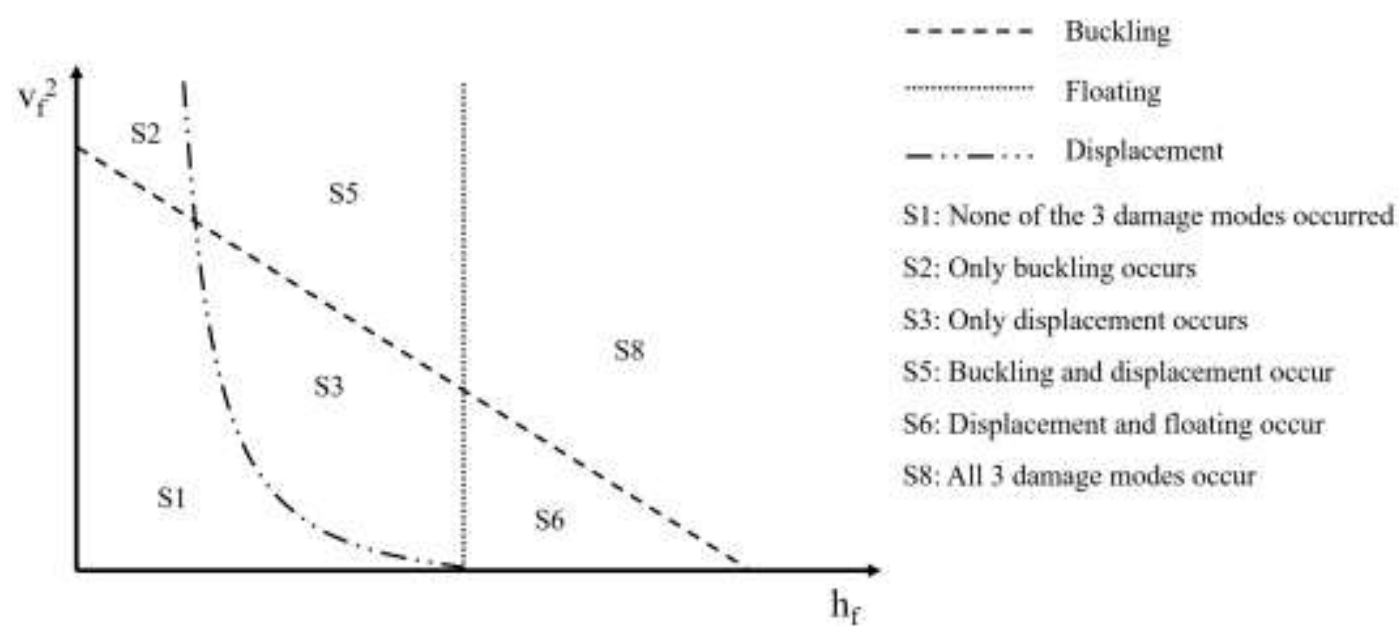

(b) without pipeline connection

Fig. 4. Vulnerability curve of tank damage caused by flood (with (a) or without (b) pipeline connection).

iii. Hail-damage

For the damage caused by hail, we can get the following form from $L S E_{\mathrm{hy}}$ :

$$
\frac{d^{2} \sin \alpha}{\cos ^{2} \alpha}=k_{6}
$$

where the incidence angle $\alpha$ meets:

$$
\tan \alpha=\frac{v_{x}}{k_{7} \sqrt{d}}
$$

Eq. (28) is a transcendental function and it's difficult to draw the curve.

\subsubsection{Resistance against damage}

Based on LSEs, we can analyze what kind of storage tank is more resistant to damage under the influence of natural disasters, or how the parameters of storage tank affect the limit state of damage. Taking the LSE of tank buckling caused by flood as an example, when $L S E_{f b}=0$, it can be obtained 
that:

$$
P_{l}+P_{c r}=P_{f s}+P_{f d}
$$

where the left side of Eq. (30) is the pressure generated by the liquid in the tank and the critical pressure of the tank, and the right side of Eq. (30) is the pressure generated by flood. Therefore, Eq. (36) can be viewed from such a perspective, that is, the greater $P_{l}$ and $P_{c r}$ are, the greater the pressure required for flood damage to the storage tank is. Therefore, it can be considered that the role of $P_{l}$ and $P_{c r}$ is to "resist" the damage of flood. When the pressure generated by the flood is greater than this "resistance", the damage occurs. According to Eq. (3), the value of $P_{c r}$ is related to $E, t, D$ and $H$. According to Eq. (5), $P_{l}$ is related to the density and height of the liquid. In order to express it more conveniently, the filling coefficient is defined as:

$$
\eta=\frac{h_{l}}{H}
$$

According to the physical properties of the liquid and the geometric characteristics of the storage tank, the filling factor can express not only the proportion of the liquid height to the storage tank height, but also the proportion of the liquid storage capacity to the storage tank capacity. The latter is more commonly used in practice. Through the same analysis, the influence of parameters related to storage tank and liquid on the damage resistance of storage tank can be obtained, as shown in Table $\mathbf{1 .}$

When a storage tank is selected, its height, diameter and other parameters are determined, while the filling factor is in an uncertain state. Table 1 shows that the filling factor can play a positive role in resisting all other damage types except the yield caused by hail. Therefore, the critical filling factor $\eta_{c r}$ is defined. When other parameters of natural disaster are determined, if the filling factor of storage tank reaches the critical filling factor $\eta_{c r}$, it can resist damage.

\subsection{Probabilistic damage assessment (Steps 7-8)}

Through the deterministic analysis of damage conditions, it can be directly seen that the storage tank is in a safe state or damaged state. However, in practice, the intensity of natural disasters and the properties of tanks and liquids in tanks are uncertain. For the purpose of better risk analysis, it is necessary to approximately calculate the probability of tank damage before natural disasters occur, so as to evaluate the damage risk of tanks caused by natural disasters.

\subsubsection{Uncertain parameter set (UPS)}

When evaluating the vulnerability of storage tanks to natural disasters, the physical properties of storage tanks and stored liquids are usually determined, and the filling factor of liquid in storage tanks will change, because the liquid in storage tanks will be stored or transported out. Therefore, when the natural disaster comes, the filling factor of the liquid in the storage tank is uncertain. In addition, the parameters of natural disasters are also in an uncertain state. Therefore, we extract the parameters in the uncertain state from LSEs as the uncertain parameter set for use in the subsequent damage assessment, as shown in Table 2. 
Table 1. The influence of parameters related to storage tank and liquid on the damage resistance of storage tank (“+” represents positive correlation, “-” represents negative correlation and "\" represents that the parameter doesn't affect resistance against damage).

\begin{tabular}{|c|c|c|c|c|c|c|}
\hline & $\begin{array}{l}\text { Flood-induced } \\
\text { bucking }\end{array}$ & $\begin{array}{l}\text { Flood-induced } \\
\text { floating }\end{array}$ & $\begin{array}{l}\text { Flood-induced } \\
\text { displacement }\end{array}$ & $\begin{array}{l}\text { Wind-induced } \\
\text { bucking }\end{array}$ & $\begin{array}{l}\text { Wind-induced } \\
\text { overturning }\end{array}$ & $\begin{array}{l}\text { Hail-induced } \\
\text { yielding }\end{array}$ \\
\hline $\begin{array}{c}\text { Young's } \\
\text { modulus } \\
E\end{array}$ & + & 1 & 1 & + & 1 & - \\
\hline $\begin{array}{c}\text { Tank } \\
\text { diameter } \\
D\end{array}$ & - & + & + & - & + & 1 \\
\hline $\begin{array}{c}\text { Tank height } \\
H\end{array}$ & - & + & + & - & - & 1 \\
\hline $\begin{array}{c}\text { Tank shell } \\
\text { thickness } \\
t\end{array}$ & + & + & + & + & + & + \\
\hline $\begin{array}{c}\text { Liquid } \\
\text { density } \\
\rho_{l}\end{array}$ & + & + & + & + & + & 1 \\
\hline $\begin{array}{c}\text { Filling } \\
\text { factor } \\
\eta\end{array}$ & + & + & + & + & + & 1 \\
\hline
\end{tabular}

Table 2. The Uncertain parameter set of multi-hazard scenario

\begin{tabular}{|c|c|c|c|c|}
\hline & & \multicolumn{3}{|c|}{ Uncertain parameters } \\
\hline \multirow{2}{*}{\multicolumn{2}{|c|}{ Storage tank }} & Filling factor & & \\
\hline & & $\eta$ & & \\
\hline \multirow{6}{*}{$\begin{array}{l}\text { Natural } \\
\text { disasters }\end{array}$} & \multirow[b]{2}{*}{ Flood } & Inundation depth & Velocity & Water density \\
\hline & & $h_{f}$ & $v_{f}$ & $\rho_{f}$ \\
\hline & \multirow{2}{*}{ Wind } & Velocity & Air density & \\
\hline & & $v_{w}$ & $\rho_{a}$ & \\
\hline & \multirow[b]{2}{*}{ Hail } & Diameter & Horizontal velocity & \\
\hline & & $d$ & $v_{x}$ & \\
\hline
\end{tabular}

\subsubsection{Damage assessment}

In order to analyze the probability of tank damage, it is necessary to estimate the uncertainty related to the random performance of parameters in UPS, which is usually described by probability distribution function. The probability distribution of each parameter needs to be selected in combination with the actual situation of the research object. For example, the probability distribution of filling factor is obtained from factory statistics, and the relevant probability distribution of natural disasters is obtained from local actual conditions and historical data. 
Monte Carlo simulation is applied to the probability assessment of tank damage. According to the obtained probability distribution function, a large number of UPSs are randomly generated. For each group of UPS, LSE is used to judge whether corresponding damage occurs. If $N_{0}$ groups of UPSs are generated, in which $N_{\text {damage }}$ group is damaged, the frequency of damage is approximately regarded as the probability of failure according to the Law of Large Numbers:

$$
p_{\text {damage }}=\frac{N_{\text {damage }}}{N_{0}}
$$

Based on the above, we can more flexibly select the probability distribution of parameters in UPS according to different research purposes and research objects, and quickly obtain the damage probability through Monte Carlo simulation, so as to provide expectations for decision makers.

\section{Case study}

In order to show the complete process and results of the method, one storage tank is used for example, and multiple tanks are used for comparison. For a vertical atmospheric storage tank, the risk assessment under the influence of a multiple disaster scenario is performed. Characterization of natural disasters and characterization of target equipment (storage tank T-0) are shown in Table $\mathbf{3}$ and Table 4, which are the Step 1 and Step 2. UPS is also reflected in the two tables (Step 7). The filling factor of the liquid in the storage tank is considered to be uniform distribution (Landucci et al. 2012), while the intensity parameter of natural disasters is set to normal distribution, because the intensity of natural disasters in an area often fluctuates around the average value in a real situation. Considering that strong wind will accelerate hailstones in the horizontal direction, the horizontal velocity of hailstone is related to wind speed.

As for the deterministic analysis of tank T-0 damage, in order to draw the vulnerability curve, the authors first fix the values (with filling factor $25 \%$ and flood water density $1000 \mathrm{~kg} / \mathrm{m}^{3}$ ) other than the natural disaster intensity parameters, and only consider how the key parameters (flood $\left(v_{f}, h_{f}\right)$, strong wind $\left(v_{w}\right)$, hailstone $\left.\left(d, v_{x}\right)\right)$ or their combination determine the natural disaster intensity affect the tank damage, as mentioned in Section 2.4.1. The vulnerability curve of storage tank T-0 damaged by flood is shown in Fig. 5, and the meaning of each partition is shown in Fig. 4. Since T-0 is not connected to the pipeline, the shape of its vulnerability curve is the same as that in Fig. 4 (b). Another aspect of deterministic analysis is resistance to damage. The critical filling factor diagram is used to show what filling factor the tank needs to "resist" the damage of natural disasters. The critical filling factor of tank T-0 against flood damage is shown in Fig. 6. When the critical filling factor is greater than 1, it means that the tank cannot resist damage even if it is filled with liquid. In Fig. 6, the critical filling factor greater than 1 is set to 1 .

It is also analyzed in Section 2.4.1 that it is difficult or impossible to draw the vulnerability curve for the damage caused by strong wind and hail. For tank T-0, the calculated critical wind speed required for buckling due to strong wind is very large (impossible on land), even when the tank filling factor is 0 . Some research (Portela et al. 2005; Zhao and Lin 2014) show that wind-induced buckling may occur only when the filling factor of large storage tanks is low. Storage tank T-0 is a smaller storage tank, which also shows that it has low vulnerability to strong wind. According to Eq.3, when the tank is larger, its critical pressure will be smaller, thus increasing the risk of buckling. Since the yield strength of the storage tank is fixed (235MPa), the storage tank will yield as long as the pressure caused by hailstone exceeds the yield strength. 
Table 3. Characterization of target equipment (storage tank T-0)

\begin{tabular}{lll}
\hline Parameter & Value & Unit \\
\hline Diameter $D$ & 14 & $\mathrm{~m}$ \\
Height $H$ & 11 & $\mathrm{~m}$ \\
Shell thickness $t$ & 0.01 & $\mathrm{~m}$ \\
Storage liquid density $\rho_{l}$ & 950 & $\mathrm{~kg} / \mathrm{m}^{3}$ \\
Filling factor $\eta$ & Uniform (1,75) (Landucci et al. 2012) & $(\%)$ \\
Young's modulus $E$ & $2.0 \times 10^{11}$ & $\mathrm{~Pa}$ \\
Poisson's ratio $v$ & 0.3 & - \\
Tank material & Q235 steel & - \\
Yield strength $Q_{s}$ & 235 & $\mathrm{MPa}$ \\
Material density $\rho_{s}$ & 7850 & $\mathrm{~kg} / \mathrm{m}^{3}$ \\
Friction coefficient $\mu$ & 0.3 & - \\
Flow resistance coefficient $C_{f}$ & 1.2 & - \\
\hline
\end{tabular}

Table 4. Characterization of natural disasters

\begin{tabular}{lll}
\hline Parameter & Value & Unit \\
\hline Flood inundation depth $h_{f}$ & Normal $(2.5,0.25)$ & $\mathrm{m}$ \\
Flood velocity $v_{f}$ & Normal $(2.0,0.25)$ & $\mathrm{m} / \mathrm{s}$ \\
Flood water density $\rho_{f}$ & Normal $(1050,250)$ & $\mathrm{kg} / \mathrm{m}^{3}$ \\
Wind velocity $v_{w}$ & Normal $(60,25)$ & $\mathrm{m} / \mathrm{s}$ \\
Air density $\rho_{a}$ & Normal $(1.25,0.0025)$ & $\mathrm{kg} / \mathrm{m}^{3}$ \\
Hailstone diameter $d$ & Normal $\left(0.02,2.5 \times 10^{-5}\right)$ & $\mathrm{m}$ \\
Hailstone horizontal velocity $v_{x}$ & Normal $\left(0.5 v_{w}, 6.25\right)$ & $\mathrm{m} / \mathrm{s}$ \\
\hline
\end{tabular}

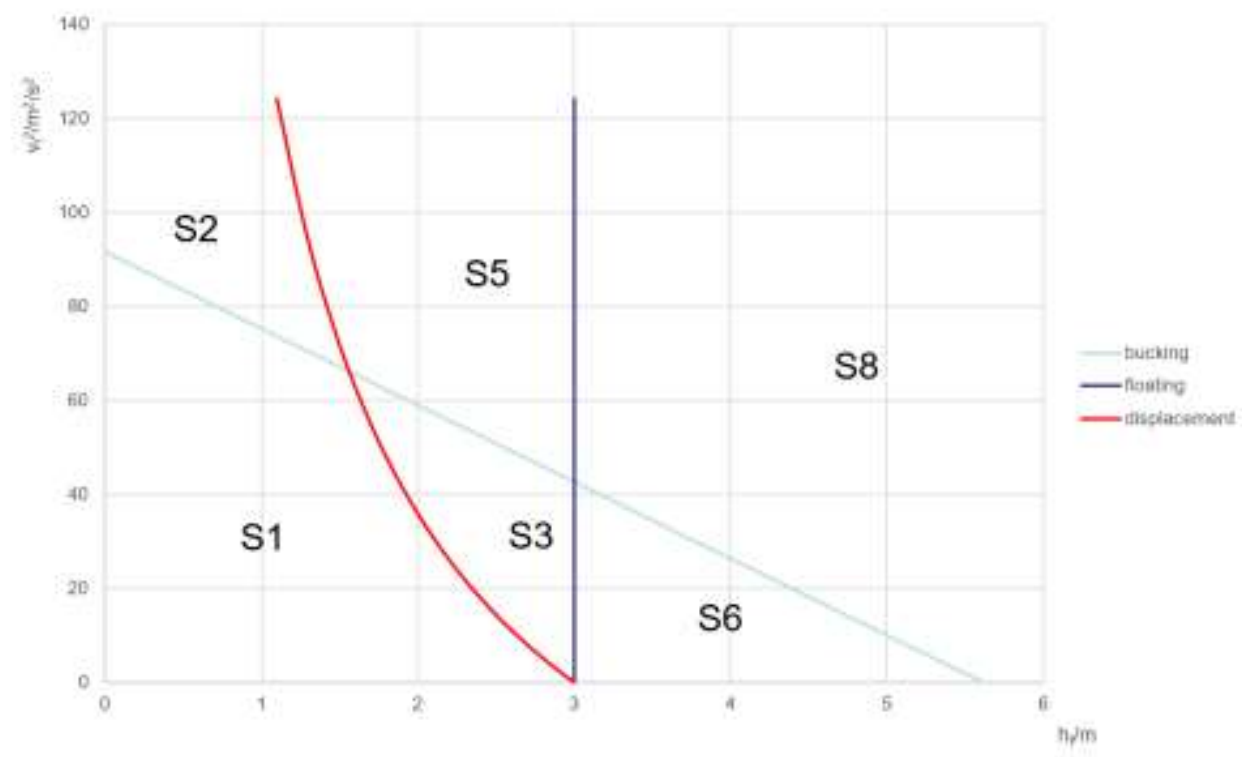

Fig. 5. Vulnerability curve of tank T-0 damage caused by flood with filling factor $25 \%$ and flood water density $1000 \mathrm{~kg} / \mathrm{m}^{3}$. 


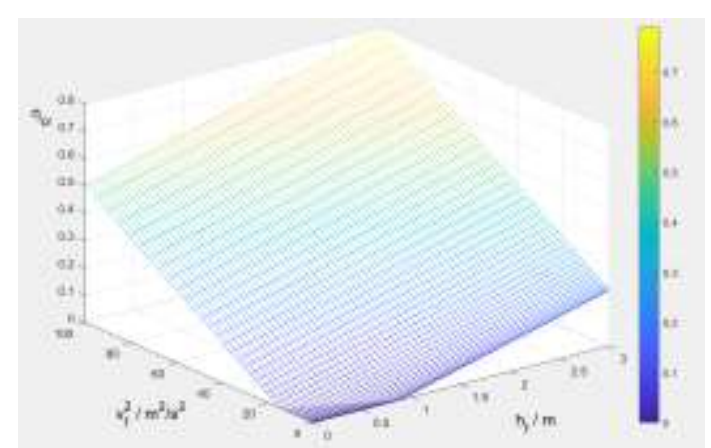

(a) bucking

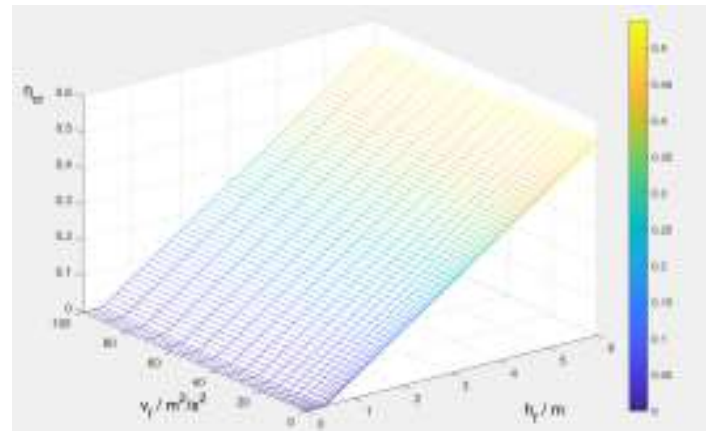

(b) floating

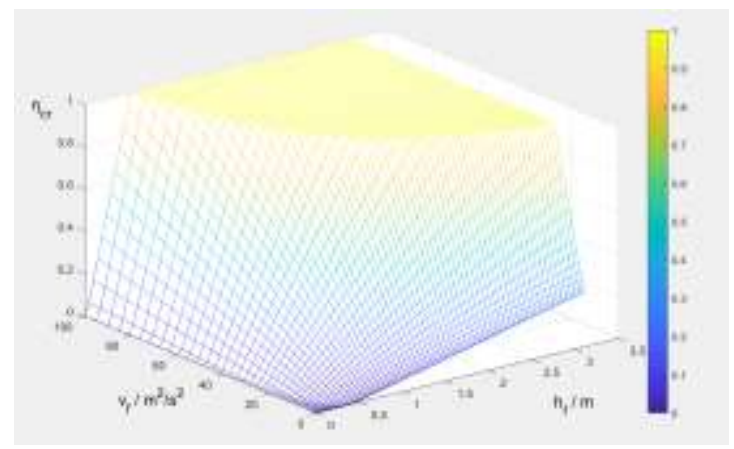

(c) displacement

Fig. 6. The critical filling factor of tank T-0 against flood damage with (a) bucking (b) floating (c) displacement.

As for the probabilistic analysis of tank damage, the damage probability of each damage type is obtained by Monte Carlo simulation according to the guideline in Section 2.5.2. For better comparison, vertical atmospheric storage tanks in a storage tank farm (Wei et al. 2016) are used to calculate the damage probability. The layout of storage tanks is shown in Fig. 7. The parameters of storage tank and storage liquid are shown in Table 6, and the other parameters are the same as those in Table 3. For each group of storage tanks, 100000 groups of UPS are used for simulation. It can be seen from the damage probability of each storage tank in Table 6 that the three damage types caused by flood are not independent of each other (because the probability of no damage is not equal to the product of the probability of no damage of each damage type). Since wind will accelerate hailstone, it is obvious that the probability of hail damage will be affected by wind speed (also reflected in Table 4). In addition, it can also be seen from Table $\mathbf{6}$ how the parameters of the storage tank affect the ability of the storage tank to resist damage. When a certain parameter has a positive effect on the resistance to damage, the damage probability will decrease. The results presented in Table 6 can qualitatively verify the impact of the parameters listed in Table 1. For example, tank groups T1 $\sim$ T6 and tank groups T7 $\sim$ T12, when other parameters are the same, the group with higher liquid storage density has lower damage probability. For another example, when the size of the tank is large, the probability of wind-induced buckling is significantly higher than that of the small-size tanks. 


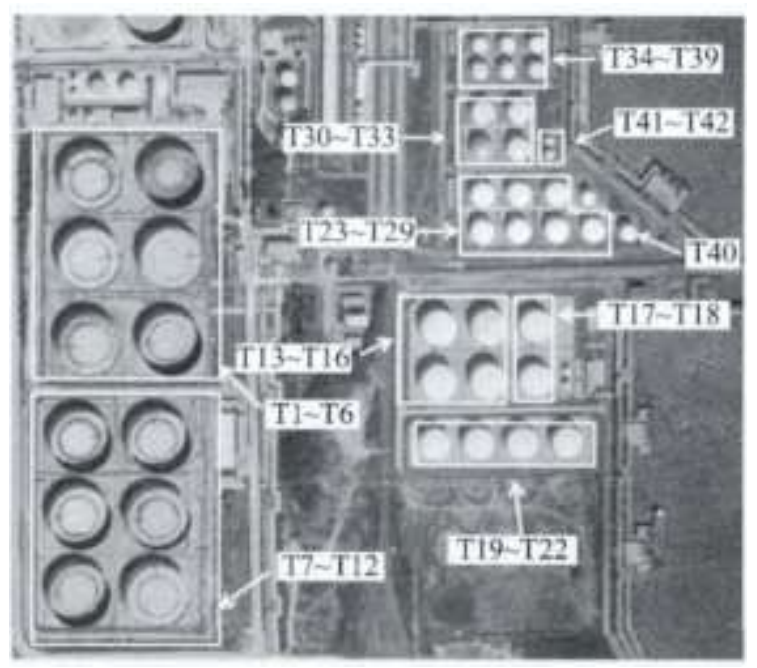

Fig. 7. The layout of storage tanks in a tank farm.

Table 5. Damage probability of storage tanks caused by natural disaster.

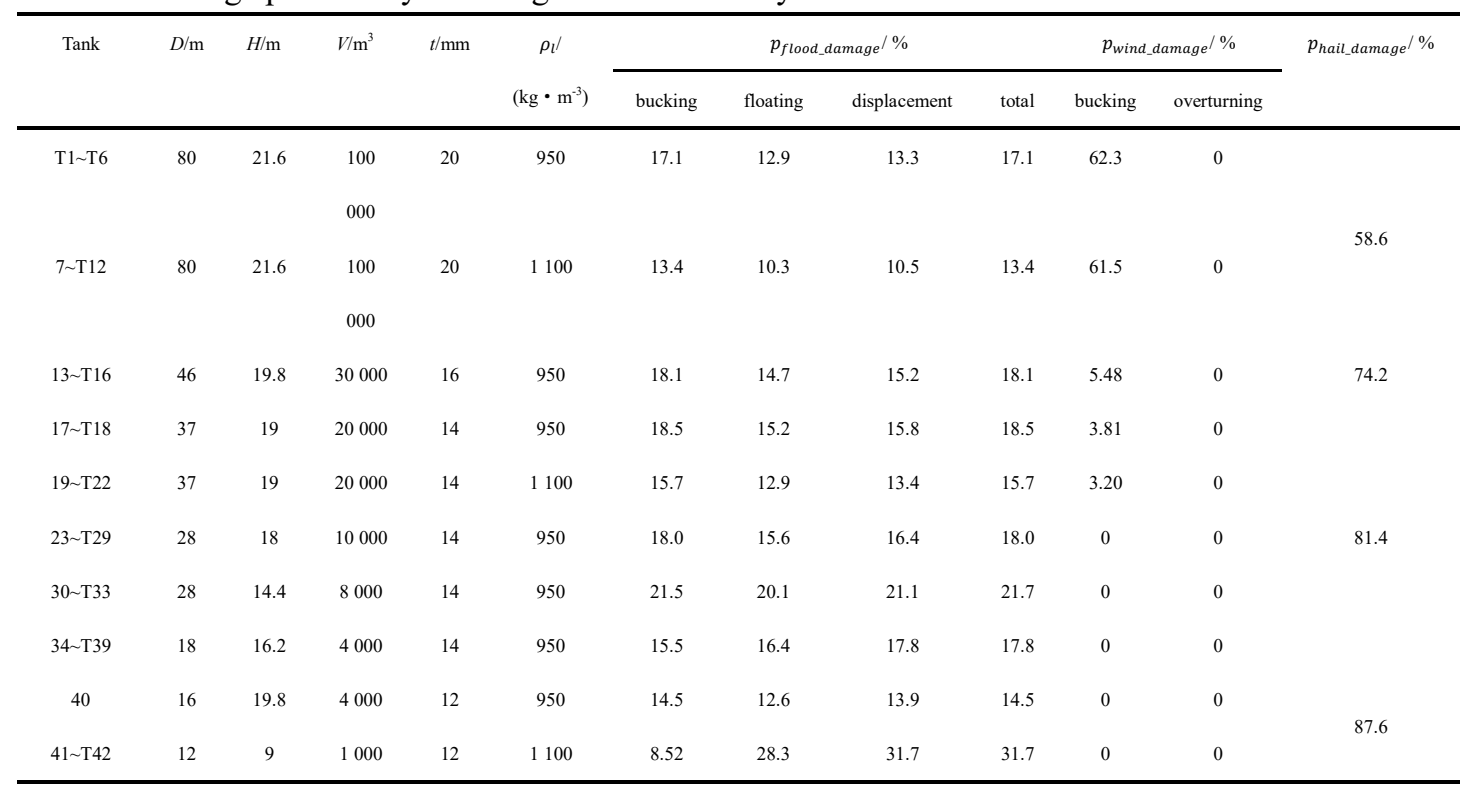

\section{Conclusions}

In the present research, a simplified but sound methodology is proposed to rapidly and flexibly evaluate the vulnerability of vertical atmospheric storage tanks to multi-hazard scenarios. The method consists of 8 steps, the most important of which is simplified physical models and limit state equations. Based on the existing flood damage models and wind induced tank buckling model, new simplified physical models of wind-overturning and hail-buckling are constructed. In addition, the assessment process of tank vulnerability is shown from two aspects: deterministic analysis and probabilistic analysis. The uncertain parameter set proposed in the method and the Monte Carlo simulation method can help to purposefully analyze the impact of various parameters, and can be flexibly applied to other multi-hazard scenarios and other industrial facilities.

A case study of a vertical atmospheric tank and a tank farm shows the proposed methodology and the calculation results. The results take into account the possible dependence between damage modes (for 
example, the 3 damage modes caused by floods are not independent) and the interaction between natural disasters (for example, wind speed affects the speed of hailstone). Through the calculation of vulnerability curve and critical filling factor, we can quickly judge whether the storage tank is safe in a multi-hazard scenario. The calculation of damage probability shows the risk of damage to storage tanks caused by natural disasters.

The present research only focuses on the analysis of the damage process of storage tanks caused by multiple natural disasters, but does not involve the process from damage to failure (LOC), which can be further implemented in future research. In addition, in order to achieve rapid risk assessment, the physical models of this study adopt some simplified assumptions, which can be refined for more accurate risk analysis. What's more, the method is also applicable to Natech events including other natural disasters or other industrial facilities with new physical models developed.

\section{Acknowledgments}

The authors are grateful to The National Science Fund for Distinguished Young Scholars of China (71725006) and National Natural Science Foundation of China (72034004) for funding this research. The authors also want to thank several persons who contributed to discussions, critics, and explanations.

\section{References}

Antonioni, G. , Bonvicini, S. , Spadoni, G. , \& Cozzani, V. . (2009). Development of a framework for the risk assessment of Na-tech accidental events. Reliability Engineering \& System Safety, 94(9), 1442 1450 .

Cruz, A. M. , \& Krausmann, E. . (2009). Hazardous-materials releases from offshore oil and gas facilities and emergency response following hurricanes Katrina and Rita. Journal of Loss Prevention in the Process Industries, 22(1), 59-65.

Cruz, A. M. , \& Okada, N. . (2008). Methodology for preliminary assessment of Natech risk in urban areas. Natural Hazards, 46(2), 199-220.

Cruz, A. M. , Krausmann, E. , \& Franchello, G. . (2011). Analysis of tsunami impact scenarios at an oil refinery. Natural Hazards, 58(1), 141-162.

Elisabeth, KrausmannFesil, \& Mushtaq. (2008). A qualitative Natech damage scale for the impact of floods on selected industrial facilities. Natural Hazards.

European Committee for Standardization. (2007) Eurocode 3: design of steel structures-Part 4-1: design of steel structures: silos (EN 1993-4-1). Brussels, Belgium.

Godoy, L. A. . Performance of Storage Tanks in Oil Facilities Damaged by Hurricanes Katrina and Rita. Journal of Performance of Constructed Facilities,2007,21(6):441-449.

Greiner, R. , \& Derler, P. . (1995). Effect of imperfections on wind-loaded cylindrical shells. Thin-Walled Structures, 23(1/4), 271-281.

Huang, K. , Chen, G. , Yang, Y. , \& Chen, P. . (2020). An innovative quantitative analysis methodology for Natech events triggered by earthquakes in chemical tank farms. Safety Science, 128.

Khakzad, N. , \& Van Gelder, P. . (2018). Vulnerability of industrial plants to flood-induced Natechs: a bayesian network approach. Reliability Engineering \& System Safety, 169(jan.), 403-411.

Landucci, G. , Antonioni, G. , Tugnoli, A. , \& Cozzani, V. . (2012). Release of hazardous substances in 
flood events: damage model for atmospheric storage tanks. Reliability Engineering and System Safety, 106, 200-216.

Landucci, G. , Necci, A. , Antonioni, G. , Tugnoli, A. , \& Cozzani, V. . (2014). Release of hazardous substances in flood events: damage model for horizontal cylindrical vessels. Reliability Engineering \& System Safety, 132(dec.), 125-145.

Milazzo MF, Ancione G, Basco A, Lister DG, Salzano E, Maschio G. (2013). Potential loading damage to industrial storage tanks due to volcanic ash fallout. Natural Hazards, 66(2), 939-953.

Olivar, O. , Mayorga, S. Z. , Giraldo, F. M. , Snchez-Silva, M. , Pinelli, J. P. , \& Salzano, E. . (2020). The effects of extreme winds on atmospheric storage tanks. Reliability Engineering and System Safety, 195.

Portela, G., \& Godoy, L. A. . (2005). Wind pressures and buckling of cylindrical steel tanks with a conical roof. Journal of Constructional Steel Research, 61(6), 786-807.

Potter, T. D. , \& Colman, B. R. . (2003). Handbook of weather, climate, and water.

Qin, R. , Zhu, J. , \& Khakzad, N. . (2020). Multi-hazard failure assessment of atmospheric storage tanks during hurricanes. Journal of Loss Prevention in the Process Industries, 68, 104325.

Schoenherr, T. F. . (2015). Calculating the Impact Force of Supersonic Hail Stones Using SWAT-TEEM. Springer International Publishing.

Showalter, P. S., \& Myers, M. F. (1994). Natural Disasters in the United States as Release Agents of Oil, Chemicals, or Radiological Materials Between 1980-1989: Analysis and Recommendations. Risk Analysis, 14(2), 169-182.

Sioutas, M. . (2017). Hail Characteristics and Cloud Seeding Effect for Hail Suppression in Central Macedonia, Greece. Springer International Publishing.

Timoshenko, S. P. , \& Gere, J. M. . (1963), Theory of elastic stability.

Wang, J. , He, Z. , \& Weng, W. . (2020). A review of the research into the relations between hazards in multi-hazard risk analysis. Natural Hazards, 1-24.

Xu, Y., Yang, Y. , \& Zhu, P. . (2005) Spherical tanks and large storage tanks. Beijing: Chemical Industry Press.

Zhao, Y. , \& Lin, Y. . (2014). Buckling of cylindrical open-topped steel tanks under wind load. ThinWalled Structures, 79(jun.), 83-94. 